\title{
Retrograde Jejunogastric Intussusception (RJGI): A Life- Threatening Complication after Gastric Bypass Surgery
}

\author{
IFARUK $^{\mathrm{a}}, \mathrm{SF}^{\mathrm{K} A B I \mathrm{R}^{\mathrm{b}}}{ }^{\mathrm{b}}$ SM ALAM $^{\mathrm{c}}$, KABMAAHASAN $^{\mathrm{d}}$
}

Summary:

Retrograde jejunogastric intussusception (RJGI) after gastric bypass surgery is a rare but potentially life threatening complication. This complication may develop after simple gastrojejunostomy, after lower partial resection of stomach with gastrojejunostomy (Billroth-II gastric surgery) or after Roux-en-Y gastric bypass. Among the three anatomic type of jejunogastric intussusception (JGI), type-II is the commonest variety. The acute form is a surgical emergency. Mortality rate is very high. Little is known about the mechanism but many literatures indicate abnormal motility may be a cause. A 50 year old male presented to us with a three month history of repeated vomiting and one day of upper mid-abdominal pain. He had a history of gastric bypass for pyloric stenosis 12 years

Introduction:

Retrograde jejunogastric intussusception (RJGI) after gastric bypass surgery is a rare but potentially life threatening complication. ${ }^{1,2}$ This complication may develop after simple gastrojejunostomy, after lower partial gastrectomy with gastrojejunostomy (Billroth-II gastric surgery) or after Roux-en-Y gastrojejunostomy. There are three anatomic types of jejunogastric intussusception that may develop as complication of the gastrojejunal anastomosis. ${ }^{3}$ In Type I, the afferent loop alone may intussuscept into the stomach. In Type II, the efferent loop may undergo retrograde intussusception and either stops short of or pass through the gastrojejunostomy stoma and in Type III, both afferent and efferent loops together may intussuscept into the stomach. Type II is the commonest variety. Little is known about the

a. Dr. Imtiaz Faruk, Associate Professor, Department of Surgery, Sir Salimullah Medical College, Dhaka

b. Dr. Sheikh Firoj Kabir, Associate Professor, Department of Surgery, Tairunnessa Memorial Medical College, Gazipur, Dhaka

c. Dr. Syed Mahbubul Alam, Professor and Head, Department of Surgery, Sir Salimullah Medical College, Dhaka

d. Dr. Kh. ABM Abdullah Al Hasan, Junior Consultant (Casualty), Dhaka Medical College Hospital, Dhaka

Address correspondence to: Dr. Imtiaz Faruk, Associate Professor, Department of Surgery, Sir Salimullah Medical College, Dhaka-1100, Bangladesh, Mob-01819231809, e- mail: imtiazfaruk69@yahoo.com

Received: 28 September, 2013

Accepted: 13 October, 2014 back. Diagnosis was confirmed by upper GI endoscopy. At laparotomy type II retrograde jejunogastric intussusception was identified. En-block resection of affected segment of jejunum and lower part of the stomach was done followed by Roux-en-Y reconstruction. RJGI is a rare complication of gastric bypass surgery. Early diagnosis is imperative. High index of suspicion is therefore important. Barium meal $X$-ray, ultra sonogram, enhanced CT scan occasionally be diagnostic, but endoscopy is certainly diagnostic in experienced hand. Laparotomy is mandatory. Surgical options include simple reduction, en-block resection and/or plication.

Key word - intussusception, jejunogastric, retrograde.

(J Banagladesh Coll Phys Surg 2015; 33: 161-165)

mechanism but many literatures suggest abnormal motility may be a cause. JGI can occur at any time after the gastric operation. ${ }^{4}$ Presentation may be acute or chronic. The acute form is a surgical emergency. Mortality may be high (10 to $50 \%$ ) if not treated promptly. ${ }^{3,5}$ Barium meal X-ray, ultra sonogram, enhanced CT scan occasionally be diagnostic, but endoscopy is certainly diagnostic in experienced hand. ${ }^{6}$ A case report of retrograde jejunogastric intussusception 12 years after vagotomy and gastrojejunostomy for pyloric stenosis is presented here.

\section{Case Report:}

A 50 year old male presented to us with a three month history of repeated bilious vomiting and one day of upper mid-abdominal pain. He had a history of vagotomy and gastrojejunostomy for pyloric stenosis 12 years back. The gastrojejunostomy was performed in conventional posterior, short loop, isoperistaltic and retro-colic fashion. The patient had been relatively asymptomatic since that procedure. Initial diagnosis was acute abdomen. After one day of fluid resuscitation his physical condition became hemodynamicaly stable, but pain was persistent and poorly relived by pethidine. Nausea and vomiting were associated symptoms. His vital signs showed a heart rate of 100 beats per minute. Abdominal examination showed a diffuse tender epigastric lump, but no signs of generalized peritonitis. White blood cell count was 9500, serum amylase was 472 U/L. USG of whole abdomen showed distended bowels with huge fluid collection in the stomach? gastric outlet obstruction (Fig.-1). 


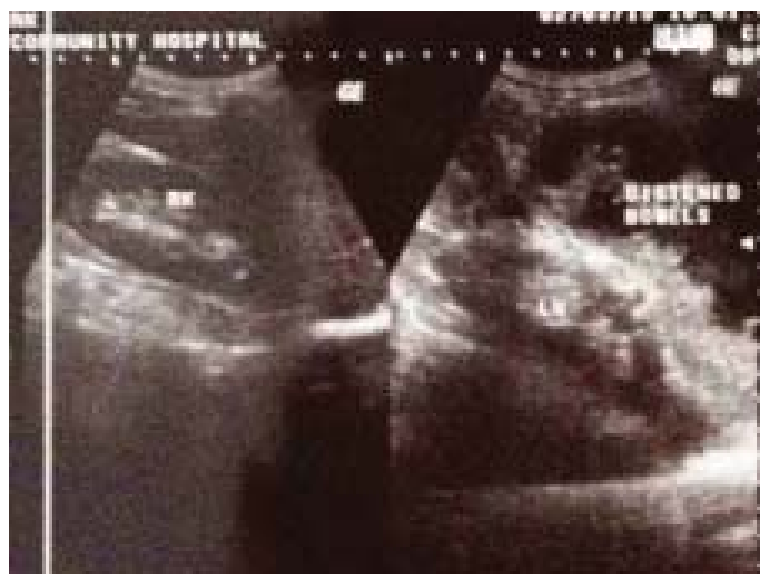

a

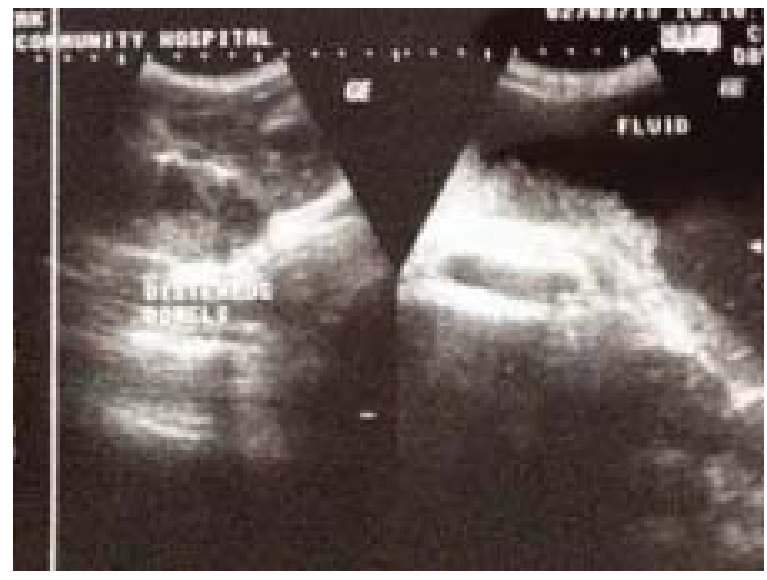

b

Fig.-1: (a) Distended bowels, (b) Fluid collection in the stomach

Endoscopy of upper GIT was done and findings are shown in fig.-2, the pertinent finding was lumen of oesophagus and stomach contains huge amount of (1.5 L) brown color, foul smelling fluid. After aspiration, loops of jejunum became visible within the lumen of the stomach which was protruded through the gastrojejunostomy stoma. Part of the loop was blackish in color.

Then the diagnosis was made retrograde jejunogastric intussusception (RJGI). The decision of urgent laparotomy was taken. Figure-3 shows the findings at laparotomy. On exploration, type II retrograde jejunogastric intussusception was identified. The afferent loop (bilio-pancreatic limb) was markedly dilated. There was jejuno-jejunal intussusception about ten $\mathrm{cm}$. distal to the previous gastro jejunostomy site, which in turn intussuscepts into the gastric lumen through the stoma

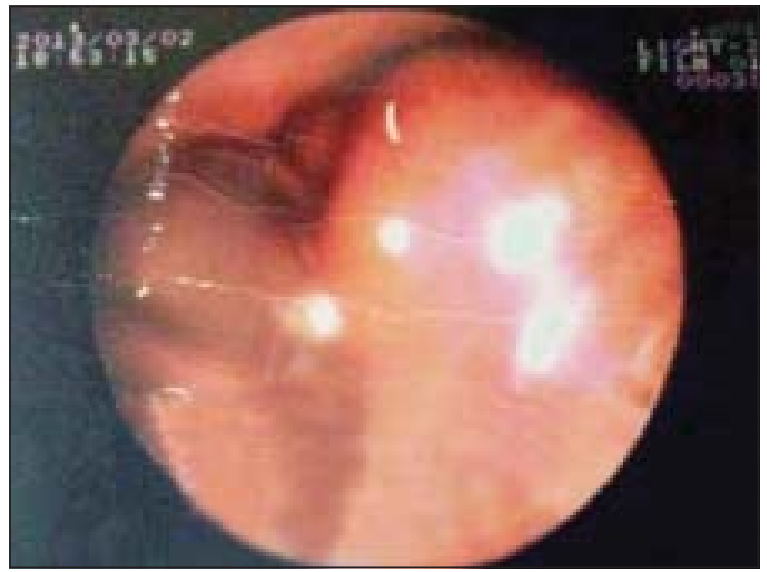

a and causing obstruction to the afferent loop also. After gastrotomy through the anterior wall, the interior of stomach was inspected. The intussusceptum consisted of jejunum. Part of jejunum was necrotic. No lead point was found. Gastric wall appeared normal. En-block resection was done (affected part of jejunum along with lower part of the stomach including the stoma was excised). Duodenal stump was closed and the small bowel was reconstructed by creating a side to side, posterior, retro-colic anastomosis between the Roux limb and gastric remnants using the linear cutter stapler. About $10 \mathrm{~cm}$ distal to this anastomosis, the bilio-pancreatic limb was anastomosed with the jejunum in end to side manner by hand swing. A naso-gastric tube was kept inside the gastric remnants. The patient did well in the post-operative period and was discharged on $12^{\text {th }}$ post-operative day.



$\mathrm{b}$

Fig.-2: (a) Loops of jejunum inside the stomach, (b) Part of jejunal loop becam gangrenous inside the stomach 


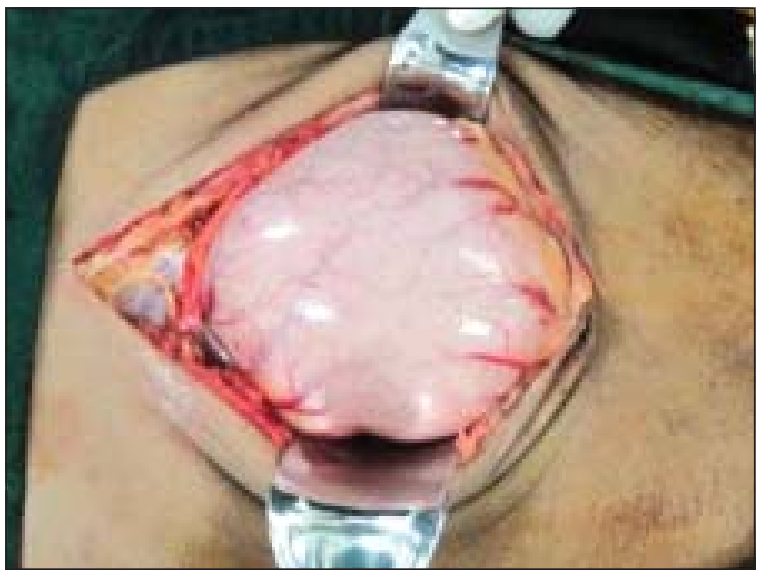

a



C

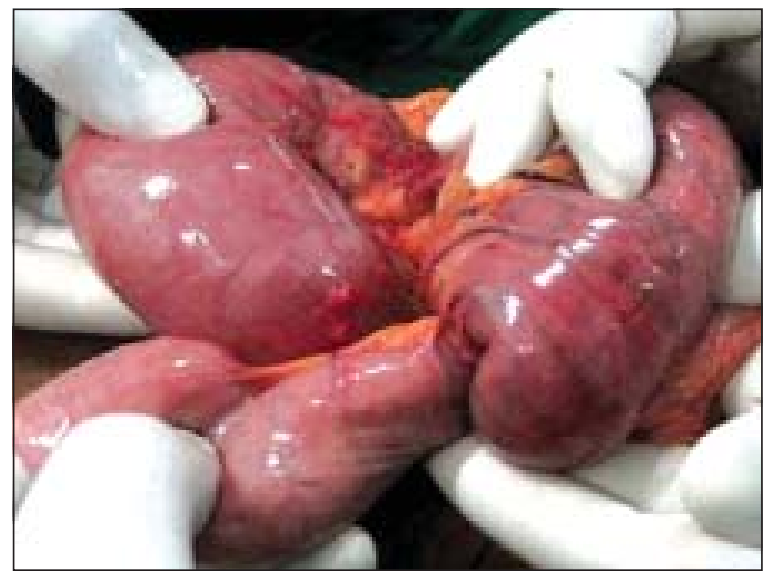

b

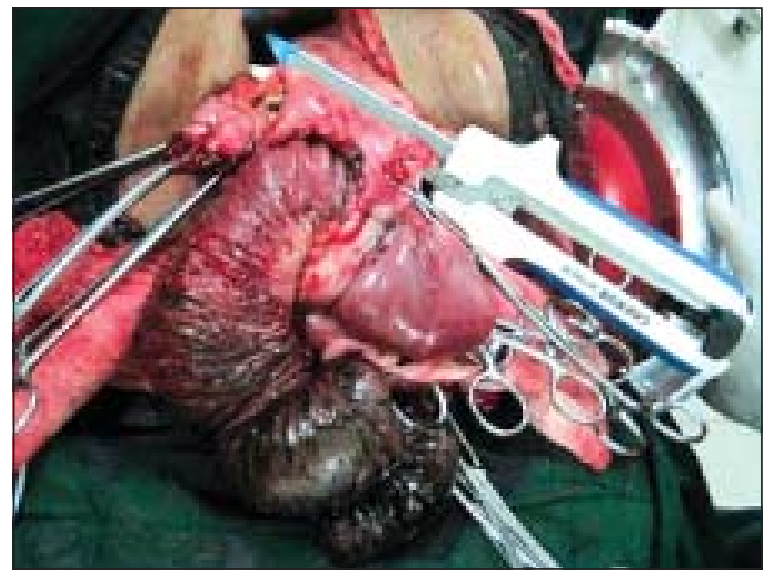

d

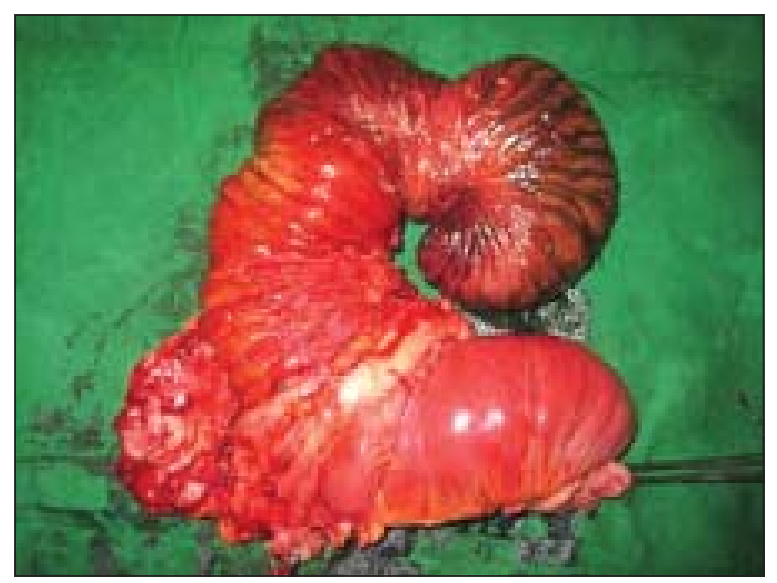

e

Fig.-3: (a) Distended stomach, (b) Jejuno-jejunal intussusception, (c) Jejunal loop after gastrotomy, (d) Division of stomach by linear cutter, (e) Resected specimen 


\section{Discussion:}

Intussusception is a rare event in adult. ${ }^{7}$ Among the post-operative complications of gastrectomy or gastrojejunostomy retrograde jejunogastric intussusception (RJGI) is rear complication. RJGI was first described by Bozzi in 1914. ${ }^{8}$ This complication has been observed, either after simple gastroenterostomy or after partial resection with Billroth-II or R-Y reconstruction and may occur after several years of gastric surgery. According to Shackman, ${ }^{1}$ three anatomic types of jejunogastric intussusception may occur as complication of the anastomosis. Type II is the commonest variety. This rare complication following gastric bypass surgery has the potential of bowel obstruction, strangulation, gangrene, perforation, subsequent sepsis and death. ${ }^{9}$

Intussusception causes about $1 \%$ of small bowel obstructions in the adult patient and most of the cases, it has been associated with a definable bowel lesion. Most intussusceptions are antegrade type. But following gastric bypass surgery, the intussusceptions are more often retrograde and are not associated with a bowel lesion or lead point. The mechanism of jejunogastric intussusception is poorly understood. ${ }^{10}$ Suggested underlying causes include - a long afferent loop, jejunal spasm with abnormal motility, increased motility of efferent loop, adhesions leading to intussusception of a more mobile segment into fixed segment, widening of upper jejunum, causes of increased intra-abdominal pressure like vomiting, pregnancy and labor, dilated atonic stomach and retrograde peristalsis.

Mechanical causes are also been suggested, ${ }^{11}$ among them are adhesions to the mesocolon, a sucking action of the stomach where the stoma is narrow, too large a stoma, jejunal stenosis with obstruction facilitating antiperistalsis and other technical imperfections are important. Once the process has been started, however, its dynamics are easily understood. The point of initial invagination may be at, proximal to or distal to the gastroenterostomy stoma. As peristalsis (afferent loop) or antiperistalsis (efferent loop) continues, more jejunum is pushed into the stoma. In acute type, the neck is tight so the chance of strangulation of the intussuscepted loop is more.

The presentation of RJGI is of two typical patterns, either as an acute and fulminating process or as a chronic and intermittently recurrent one. ${ }^{1,10}$ In acute form the common presentation is upper abdominal pain, bilious vomiting, hematemesis and epigastric lump. Visible peristalsis and upper abdominal rigidity are often present. The usual pre-operative diagnosis has been high intestinal obstruction, acute pancreatitis or acute abdomen. It should be pointed out that a sudden onset of epigastric pain, vomiting, subsequent hematemesis and a palpable epigastric lump in a patient with a previous gastric surgery are thought as the classical triad of jejunogastric intussusception. ${ }^{12}$ Except hematemesis all other features were present in our case. In chronic recurrent form symptoms are vague, transient often confusing and subside spontaneously. ${ }^{13}$ Repeated episodes are usually accompanied with nausea and vomiting.

Early diagnosis is imperative. A history of gastric surgery is an important clue. Plain X-ray abdomen usually not helpful, mild to moderate elevation of serum amylase is a non-specific finding as in our case. Barium meal X-ray is very helpful. ${ }^{14}$ The oval or round filling defect in the stomach with its base at the site of gastroenterostomy stoma and a uniform pattern of curved lines suggestive of jejunal mucosa is quite pathognomonic of JGI. Ultrasonography can show intragastric tubular images with or without peristalsis. Enhanced computed tomography (CT) of abdomen is one of the most reliable method of diagnosis. ${ }^{15,16}$ Findings of a dilated stomach with an intragastric filling by bowel loops suggestive of JGI. Edward described CT with contrast carries an accuracy of up to $80 \% .{ }^{17}$ However endoscopy performed by someone familiar with this rare complication, is certainly diagnostic as in the present case. ${ }^{6}$

Laparotomy is mandatory. Although definitive, corrective and preventive measures have not yet been established. Surgical options include simple reduction, en-blocked resection with RY reconstruction and/or plication.

\section{Conclusion:}

After gastric bypass surgery, retrograde jejunogastric intussusception is a rare but potentially life threatening complication. This complication may occur after several years of gastric surgery. In acute form common presenting symptoms are acute upper abdominal pain, bilious vomiting, haematemesis and epigastric lump. Endoscopy appears to be the most effective diagnostic 
tool. Laparotomy is mandatory. Surgical options remain controversial. High mortality is due to delay in diagnosis and poor preparation of patient. Early diagnosis with a high index of suspicion and prompt treatment are therefore important.

\section{References:}

1. Archimandritis AJ, Hastzopoulas N, Hatzinikolaou N, et al. Jejunogastric intussusception presented with hematemesis : a case presentation and review of literature. BMC Gastroenterology 2001;1:1-4.

2. Bapaye $\mathrm{M}$, Kolte $\mathrm{S}$, Pai $\mathrm{K}$, et al. Jejunogastric Intussusception presenting with outlet obstruction. Indian J Gastroenterol 2003;22:31-2.

3. Shackman R.: Jejunogastric Intussusception. Brit. J. Surg.1940; 27:475-480.

4. Conklin EF, Markowitz AM. Intussusception-a complication of gastric surgery. Surgery. 1965;57: 480-488.

5. Sibley WL. Chronic intermittent intussusception through the stoma of a previous gastro-enterostomy. Proc Staff Meet Mayo Clin. 1934;9:364-365.

6. Kallen R, Graffner H, Jonsson Per-Ebbe J. Jejunogastric intussusception through the enteroanastomosis after gastric resection. Case report. Acta Chir Scand. 1986;152:637-640. [PubMed]

7. Coster D, Sundberg S, Kermode D, Beitzel D, Noun S, Severidt M. Small Bowel Obstruction Due to Antegrade and Retrograde Intussusception after Gastric Bypass: Three Case Reports in Two Patients, Literature Review, and Recommendations for Diagnosis and Treatment. Surg Obes Relat Dis. 2008; (4):69-72.
8. Bozzi E. Annotation. Bull Acad Med. 1914;122:3-4.

9. Simper S, Erzinger J, Mckinlay R, Smith S. Retrograde (Reverse) Jejunal Intussusception Might not Be Such a Rare Problem: A Single Group's Experience of 23 Cases. Surg Obes Relat Dis 2008; (4):77-83.

10. Bakhash K, Igbinovia A, Egere JU, Ali A, Butt MS, Rehan AM. Jejunogastric intussusception: A rare cause of life threatening hematemesis. Annals Saudi Med 1997; 17:328-30.

11. Irons HS, Lipin RJ. Jejuno-gastric intussusception following gastroenterostomy and vagotomy. Ann Surg. 1955;141:541-546. [PMC free article] [PubMed]

12. Foster DG. Retrograde jejunogastric intussusception-a rare cause of hematemesis. AMA Arch Surg. 1956;73:10091017. [PubMed]

13. Olsen AK, Bo O. Intussusception as a complication of partial gastrectomy-a case report. Acta Chir Scand. 1978;144:405-408. [PubMed]

14. Jaaskelainen V. Retrograde intussusception after certain gastric operations. Ann Chir Gynaecol. 1954;5 (Suppl):129-135.

15. Shaw D, Huddleston S, Beilman G. Anetrograde Intussusception following Laparoscopic Roux-en Y: A Case Report and Review of the Literature. Obesity Surg. 2009; (20):1191-1194.

16. Majeski J, Fried D. Retrograde intussusception after Rouxen-Y gastric bypass surgery. J Am Coll Surg 2004; 199(6):988-9.

17. Edwards MA, Grinbaum R, Ellsmere J, Jones DB, Schneider $B E$. Intussusception after Roux-en-Y gastric bypass for morbid obesity: a case report and literature review of rare complication. Surg Obes Relat Dis 2006; 2(4):483-9. 